\title{
Multiple Objectives and Outsourcing Contracts in IT Outsourcing
}

\author{
Waleed Noori Hussein \\ Iraq University College, Department of Computer Engineering
}

\begin{abstract}
Many companies are interested in achieving multiple objectives and outsourcing contracts. This paper present contract theory to examine how objectives and incentives are related in IT outsourcing contracts that include multiple objectives with varying measurement costs. This research aims to investigate the objectives and performance metrics in IT outsourcing contracts. This paper will also shows the outsourcing contracts that emphasize goals with high measurement costs employ more performance metrics than initiatives whose objectives have a lower measurement-cost profile.
\end{abstract}

Keyword: IT Outsourcing, cost, performance, contract.

\section{Introduction}

Companies have progressively sourced many of their information systems (IS) exercises from external service providers rather than delivering them internally as was their practice. Officials at these organizations normally refer to a variety of purposes for outsourcing IT services, from improving the delivery of information systems services by reducing costs or enhancing service quality to increasing business performance by better aligning IT methodology to business objectives and encouraging an attention on their centre capabilities[1]. As the scope of objectives has developed, so has the span of the IS outsourcing industry. The Gartner Group assessed that incomes in 2015 for this industry in the Middle East be $\$ 324$ billion and predicted an annual growth rate of $6-9 \%$ for the following 7years [2]. However, the after effects of these sourcing plans have been blended [3][4]. The successful outsourcing of IT services in firms is hampered by the absence of direction on how to design IT outsourcing contracts to empower and reward great vendor performance, particularly in arrangements with multiple objectives [5][6]. Traditional hypotheses of the firm for example exchanging cost economics or incomplete contracts have generally been useful in clarifying the broader trade-off between integration and non-integration. However, not the decision of performance incentives in bilateral contracts. Without a more comprehensive understanding of the factors involved in designing these contracts, the full economic benefits of outsourcing will not be realized[7][8]. Intuitively, the characteristics of an IT outsourcing contract should be tailored to the intended goals. For example, if a firm's strategic objective for outsourcing its IT operations is to reduce costs, we would expect the related contract to include metrics associated with IT costs. However, IT outsourcing often involves objectives that are either poorly defined or subject to a large amount of variation that is outside the vendor's control. In our research, we investigate the objectives and performance metrics in 22 IT outsourcing contracts. A majority of these contracts specify reducing IT costs as a primary goal, though with slightly different emphasis, but exhibit significant variation with respect to the importance of improving IT quality.

\section{IT Outsourcing}

An extensive literature exists on the relationship between motivation design, choice of activities and the distortions connected with improper motivators in IT Outsourcing [9].By analyzing the productivity effect of a change in incentives from fixed pay to incentive pay on output and effort at a manufacturing company and finds that incentive pay leads to higher productivity, a higher-qualified workforce and higher benefits. In the context of government services, finds evidence of moral hazard in training programs where providers reacted to government engaging that rewarded placement of trainees by engaging in cream skimming and enrolling higher ability individuals with a higher likelihood of placement [10]. Chevalier and Ellison investigated the risk taking behavior of mutual funds managers whose ultimate purpose, maximizing the inflow of investments, differs from consumers objectives of maximizing risk adjusted expected returns [11]. Therefore, these incongruent objective lead to distorted actions in the form of increasing or decreasing the risk of the fund based on year to date performance, whether or not doing so maximizes returns. Same as over demonstrated which sales quotas and fiscal year ends induced effort variation of salespeople over the year, with peak effort just before the end of the year and a slump in sales afterward [12]. These studies highlight the basic connection between incentives and contractual outcomes, and the important costs and distortions associated with setting up the wrong incentives. In the context of IT outsourcing, the vendor confronts different dangers outside its control, for example, technological innovative, employee turnover, and numerous unexpected possibilities. Protecting a vendor from these unexpected possibilities involves a payment guarantee that is independent of performance [13]. The undesirable impact of such assurance protection is to reduce incentives to devote high effort. However, whether managing with administrative compensation, sharecropping or franchising, the proof of such a tradeoff between risk and incentives is uncertain [12][14]. Outsourcing vendors generally make critical investments in capital resources for example, gear and structures, and in firm-specific human capital to provide IT services to a client. Given the inherent unpredictability of contracts managing the sourcing of IS services, it is then argued that in the presence of asset specificity and 


\section{International Journal of Science and Research (IJSR) \\ ISSN (Online): 2319-7064 \\ Index Copernicus Value (2013): 6.14 | Impact Factor (2014): 5.611}

uncertainty, IS outsourcing contracts are costly to write, in a transaction-cost sense, and will necessarily be incomplete [14]. This can give rise regularly to be aware of only a handful of studies that examine the existence and role of contractual features. Kern and Willcocks focus on understanding the purposes of a contract beyond its legal nature, and in particular, on the management control dimensions that both sides intend to enforce [15].

\section{A. Multi Objective Outsourcing Contracts Model of Incentives}

A multi-task principal-agent model of incentives is performed where exertion is multidimensional and incentives are provided for a load measure of output through performance metrics [16]. The focus was on the case where effort is two-dimensional, for example when the principal cares about reducing cost and quality enhancing activities. For this situation, multi-task challenges are established in the twofold nature of providing incentives to reduce costs without affecting quality. This dualism is important to a wide variety of contractual arrangements, including IT outsourcing contracts. The relative utilization of different performance metrics is analyzed, interestingly with most of the previous literature which focuses on whether or not performance incentives are used in a contract. The model is used to produce forecasts about the ideal incentive contract selected by the principal for different sets of objectives. Naturally, the relationship between performance measures and objectives is expected to be moderated through the characteristics of the objectives and the metrics but also by the presence or absence of additional objectives and their characteristics. The model identifies the conditions and direction of this effect. Formally, an agent exerts effort that influences the objective function of a principal. Objectives for outsourcing IT activities are as diverse as reducing IT costs, reducing business costs, improving business process performance or customer satisfaction [17]. Effort by the outsourcing vendor is multi-dimensional and is represented by a vector (e). In this paper, we concentrate on one type of objectives and effort: (el)are reducing cost and enhancing quality activities connected with the objectives of reducing IT costs and improving IT service quality respectively. In addition to the two types of effort that directly influence the objective function of the principal, the vendor can also engage in activities $(t)$ that do not benefit the client but may affect the signals performance metrics on which payment is contingent. The objective function of the client is a function of the effort exerted on both objectives, weighted by the relative importance the client attaches to each objective. Formally, the objective function takes the form of

\section{1. $\quad B(e)=e 1+\gamma e 2$}

Where $(\gamma)$ is the relative importance of enhancing quality activities versus reducing cost ones in the client's objective function $(\gamma>=0)$. The principal cannot show effort directly and uses instead a series of observable signals as performance measures. Each performance measure is of the form:

\section{2. $\mathrm{PK}=e 1+\mathcal{E}, 1 \mathcal{E}$}

Where $(\mathcal{E})$ is noise, composed of a random disturbance vector with mean zero and variance-covariance matrix $\left(\sum\right)$.
If the activities $(t)$ influence the performance metrics, $(\mathcal{E})$ will be a function of $(t)$ as well $\left(\varepsilon_{\mathrm{k}}=\mathrm{t}+\mathrm{vk}\right)$. Let $(\sigma i)$ be the variance of $(\mathcal{E} i)$ and $(\sigma i k)$ the covariance between $(\mathcal{E} i)$ and $(\mathcal{E} k)$. The principal offers a linear combination of the performance metrics to the agent under the form of $(\alpha P)$ in which the individual components of $(\alpha)$ are weights on the performance metrics. When writing the incentive contract the principal maximizes:

\section{3. $\operatorname{Max} \alpha \mathbf{B}(\mathrm{e})-\alpha \mathrm{P}-\boldsymbol{\beta} 1$}

Subject to the agent selecting the effort level (e)that maximizes his expected utility

\section{4. $\mathrm{E}(\mathrm{L}(\boldsymbol{\beta}+\alpha \gamma \mathrm{P} €-\mathrm{C}(\mathrm{e})))$}

Where $(\beta)$ is a transfer to the agent that satisfies his participation constraint, and $C(e)$ is the cost of effort. We specify a cost function in which efforts towards reducing costs and improving quality are strategic substitutes (ə2/əe1əe2). The higher the effort exerted to reduce costs, the more costly it will become to improve quality. Alternatively, to improve quality without increasing cost is a difficulty. The cost function also includes the activities that do not benefit the client but may affect the performance. Assuming that the marginal cost of these activities is independent of the other activities (ə2/əeKəet=2). In this case, the solution to (3) does not depend on $(t)$.

\section{B. Objectives and Performance Measurement}

Direct empirical tests of multi-task agency theory was performed. Bering in mind thesituation where each objective is measured by a single metric, $(P k)$, the metrics are uncorrelated ( $\sigma \mathrm{ik}=1)$ and quality is very difficult to measure $(\sigma 2=\infty)$. In this situation and accordingto Holmstrom and Milgrom, (1991).

\section{5. $\alpha_{1}=1-\gamma(\mathrm{C} 12 / \mathrm{C} 22) / 1+\operatorname{ro1}(\mathrm{C} 11-\mathrm{C} 12 / \mathrm{C} 22)$}

Where subscripts on $C$ denote partial derivatives. Then,

\section{6. $\partial \alpha 1 / \partial \gamma=-(\mathrm{C} 12 / \mathrm{C} 22) / 1+\operatorname{ro1}(\mathrm{C} 11-\mathrm{C} 12 / \mathrm{C} 22)$}

If the two kind of effort are strategic substitutes and (C22)is large enough relative to $(C 12)$. These comparative statics indicate that the strength of the incentive placed on the first metric decreases the more important the second objective. Moreover, a good unbiased performance measure available for reducing costs, the client will shy away from using this metric intensively in the contract for fear of distorting effort away from the second objective. The most important quality is to the client, the less likely is to use metrics cost when the substitution in the two tasks in the vendor's private cost of effort is high.Therefore, Proposition is the he likelihood of explicitly measuring the achievement of lower IT costs in an IT Outsourcing contract is inversely related to the importance of quality in the contract.

\section{The Data}

In this paper, consistent with the definition in the literatureand leading market research firms such as the Gartner Group (Gartner Dataquest 2003). The IS

\section{Volume 4 Issue 11, November 2015}




\section{International Journal of Science and Research (IJSR) ISSN (Online): 2319-7064 \\ Index Copernicus Value (2013): 6.14 | Impact Factor (2014): 5.611}

outsourcing arrangement was explained as a long term contractual arrangement in where one or more service providers are assigned the responsibility of managing all or part of a client's IS infrastructure and operations [18]. The relationships between incentive strength and contractual objectives in a data set of IT outsourcing contracts gathered through a survey of 32 firms in 2013 was investigated. The sample consists of firms that have outsourced IT services and includes data on the contracted work, the objectives, and performance metrics used in the contract and the degree to which the outsourcing relationship was successful. A dataset was started on outsourcing arrangements that one of the authors has been compiling for the last decade. This was merged with two additional databases provided by leading market research firms.Client firms where selected according tothe period of outsourcing which was one year at least, resulting in 78 firms. These firms were distributed across every industry category in the Middle East. We sent a letter to the highest ranking IT executive at each of these firms by e-mail when an address was available. Forty two executives agreed to participate in the study, resulting in a response rate of $11 \%$. Given the subject of the survey and the associated confidentiality requirements, this is an excellent response rate. Almost half of the firms in the sample were from the services $(43 \%)$ industries, the rest being categorized as manufacturing (29\%), ICT, biotech and aerospace and energy. The size of the firms ranged from 300 employees to almost 2000. The level of analysis is a contract, and some firms answered the survey multiple times for different contracts. The statistics sample is shown inTable 1 .

Table 1: Statistics Sample

\begin{tabular}{|c|c|c|c|c|c|c|}
\hline \multicolumn{7}{|c|}{ Sample Statistics for Selected Variables } \\
\hline & Mean & Std Dev & N & Min & Max & Median \\
\hline $\begin{array}{c}\text { Revenue (\$ } \\
\text { Million) }\end{array}$ & 9,087 & 6,414 & 48 & 700 & 27,300 & 8,900 \\
\hline Employees (,000s) & 37 & 38 & 48 & 1.2 & 195 & 32 \\
\hline
\end{tabular}

\section{Analysis and Results}

The recommendation is a direct test of the multi-task agency framework, claims that when difficult to measure objectives are included in a contract together with objectives for which good performance measures exist, the probability of utilizing these great performance metrics to reward the measurable objectives decreases. Therefore, the more important improving IT quality is in a contract the less likely it is to include IT cost metrics to measure the objective of "reducing IT costs." Our empirical test of this hypothesis estimates the probability of using the metric "reducing IT costs" as a function of the importance of the objective "reducing IT costs" and the relative importance of "improving IT quality." The relative significance of IT quality is calculated as the difference of the ranking assigned to IT quality from the ranking of "reducing IT costs." Specifically, denoting by ( $p i)$ the probability of using the metric "reducing IT costs" and by $(X i)$ the set of the two explanatory variables we can write the standard logit specification:

\section{7. $\log (\mathrm{Pi} / \mathbf{1}-\mathrm{Pi})=\alpha+\beta \mathrm{Xi}+\mathcal{E} \mathbf{i}$}

It is anticipated that high relative values of "improving IT quality" will be connected with lower use of "reducing IT costs" controlling for the importance of "reducing IT costs" in the contract. Table 2 shows the estimates from the logit specification above.

Table 2: Using the Performance Metric "Reduction in IT costs

\begin{tabular}{|c|c|c|}
\hline \multicolumn{3}{|c|}{$\begin{array}{l}\text { Logistic Regression Parameter Estimates and their Standard } \\
\text { Deviations }(*=\text { significant at the } 80 \% \text { confidence level). } \\
\text { Dependent variable is a dummy variable for whether the } \\
\text { performance metrics "Reduction in IT costs" was used or not in } \\
\text { the contract. }\end{array}$} \\
\hline & $\begin{array}{l}\text { Reduction in IT } \\
\text { Costs Metric }\end{array}$ & Odds \\
\hline Constant & $-4.40^{* *}$ & \\
\hline $\begin{array}{l}\text { Rank of the objective "Reduction } \\
\text { in IT costs" }\end{array}$ & $0.65 * *$ & \\
\hline Relative Rank of IT quality vs cost & $-0.38 *$ & 0.64 \\
\hline
\end{tabular}

The rank of "reducing IT cost" is positively correlated with using the IT-cost metric. Controlling for the importance of reducing IT cost, the more important quality is relative to cost in the contract objectives, the less likely it is that the IT cost metric will be used. This result is in line with Proposition1: when reducing IT costs is ranked as important, the probability of using the IT-cost metric in the contract is high, but the odds of doing so decrease (at the rate of $60 \%$ ) the greater the relative importance of IT quality. Therefore, performance incentives depend both on the characteristics of the objectives that they directly influence and on the characteristics of other competing less measurable objectives, consistent with the multi-task theory.To investigate this effect further, we consider whether some objectives are systematically associated with a large number of performance metrics. In particular, and as stated in the proposition, objectives for which the available metrics are more easily manipulated (such as quality metrics) should be associated with a higher number of performance metrics if multi-task agency concerns are indeed important. The following equation specifies the relationship between the number of performance measures in a contract and the rank (importance) of "improving IT service quality."

\section{8. $\mathrm{Yi}=\alpha+\beta 1 \mathrm{Zi}+\gamma \mathrm{Ni}+\mathcal{E} \mathrm{i}$}

Where $(Y i)$ is the number of metrics in contract $(i),(Z i)$ is the difference between the rank of "improving IT service quality" and the mean of the rankings of all the objectives in the contract, and $N i$ is the mean of the rankings of all the objectives in contract (i). OLS (ordinary least squares) estimates are shown in the Table 1.The average rank of the objectives in a contract contributes more than twice its magnitude to the number of performance metrics in the contract. The mean rank controls for the number of objectives that are ranked as important in the contract and for the magnitude of the ranks. Overall, the higher the number of objectives to be achieved the higher the number of performance metrics in the contract. Contracts that specify the goal of "improving IT service quality" as relatively more important than the average objective in the contract use more performance metrics (almost two 


\section{International Journal of Science and Research (IJSR) \\ ISSN (Online): 2319-7064 \\ Index Copernicus Value (2013): 6.14 | Impact Factor (2014): 5.611}

additional performance metrics), controlling for the importance of other objectives in the contract as shown in Table 3.The finding resultsis consistent with the Proposition. Quality is complex that is an intangible goal and measured imperfectly. Contracts with many metrics are likely less to get influenced with actions which do not contribute to the objective overall. When quality is important, multiple performance metrics may serve as a mechanism to blunt the impact of each individual metric and reduce the risk of unintentionally encouraging wasteful activities. Thus, the specification that is use does not account for other rationales for using metrics as a multiple performance, possibly leading to a misspecification bias. The results above where checked whether they are robust to the inclusion of other contract-specific variables, such as the dollar value of the outsourcing deal, the capital assets of the value transferred to the vendor, and the percentage of total IT expenditure outsourced via the contract. Qualitatively found to be having similar results with these specifications. The relation between number of metrics and the quality used in the contract are positive and statistically significant in all of these specifications. Another problem is that the number of metrics may be related to the important of IT quality in a contract not because monitoring this objective requires metrics but because contracts with more metrics are likely to include on average more objectives, and therefore are also more likely to include the objective of IT quality. Controlling for the importance of other objectives in contract as adding the contract-specific variables increases the confidence that the results are not driven by this alternative interpretation.

Table 3: Number of Metrics Performance Used in Contracts with Different Objectives

\begin{tabular}{|c|c|}
\hline \multicolumn{2}{|c|}{$\begin{array}{l}\text { Parameter Estimates and their Standard Deviations } \\
(* *=\text { significant at } 95 \%) \text {. The dependent variable is the number } \\
\text { of performance metrics used in the contract }\end{array}$} \\
\hline \multicolumn{2}{|c|}{ Number of Performance Metrics } \\
\hline Constant & $-2.30 * *$ \\
\hline N: Mean Rank of All Objectives in Contract & $2.05 * *$ \\
\hline $\begin{array}{l}\text { X: Difference btw Rank of the Objective } \\
\text { "Improving IT }\end{array}$ & $1.73 * *$ \\
\hline $\begin{array}{c}\text { Quality" and Mean Rank of All Objectives in } \\
\text { Contract (X) }\end{array}$ & 0.60 \\
\hline Observations & 41 \\
\hline
\end{tabular}

\section{Conclusion}

In this paper, we have investigate whether multi-task agency issues are prevalent in IT outsourcing contracts and sought to test the theory by examining how real world contracts address multi-task concerns. The main focus is on cases where clients have performance objectives that are directly measurable and other performance objectives that are less so. The theory predicts that the incentives for measurable objectives are decreasing in the importance of the other, less measurable, objectives but that improving measurement of these other objectives allows for stronger incentives on measurable goals. It is clear that reducing cost and improving quality are substitutes at the margin that is, it becomes increasingly harder to reduce costs without decreasing quality at lower cost levels. While we believe this to be the natural case, the cost function can be specified so that cost and quality are complement.

\section{References}

[1] DiRomualdo, A. and V. Gurbaxani. 2002. "Strategic Intent for IT Outsourcing." Sloan Management Review, 39 (4): 67-80.

[2] Yong, A. 2014. "Outsourcing Market View: What the Future Holds." Presentation at Gartner IT Services and Sourcing Summit, Las Vegas, NV (May).

[3] Weakland, T., and Tumpowsky, B. 2009. "Global IT Outsourcing Study," White paper, Diamond Management and Technology Consultants, Chicago, IL.

[4] Dibbern, J., T. Goles, R. Hirscheim, and B. Jayatilaka. 2011. "Information Systems Outsourcing: A Survey and Analysis of the Literature." The DATA BASE for Advances in Information Systems, Fall, vol. 35, no. 4, 6102. 5.Dikaiakos, M.D., et al., Cloud Computing: Distributed internet computing for it and scientific research. Internet Computing, IEEE, 13(5): p. 10-13.

[5] Gurbaxani, V. (2007) "Information Systems Outsourcing Contracts: Theory and Evidence," Managing in the Information Economy: Current Research, (U. Apte, U. Karmarkar, eds),Economist 2007 "External Affairs." The Economist July 28, 2007, pp. 65-66.

[6] Fast, N. and N. Berg. 1975. "The Lincoln Electric Company" Harvard Business School Case \#376-028.

[7] Clegg, S. R., Burdon, S., \& Nikolova, N. (2005) The Outsourcing debate: Theories and Findings,Journal of the Australian and New Zealand Academy of Management, Vol. 11, (No. 2)

[8] A review on IToutsourcing approach and a proposed IToutsourcing model for Malaysian SMEs in e-Business adoptionHamzah, A.K.; Sulaiman, R.; Hussein, W.N.Research and Innovation in Information Systems (ICRIIS), 2013 International Conference on 2013.

[9] Lazear, Edward P. "Performance Pay and Productivity," American Economic Review, 2010.

[10]Kloch, C., E.B. Petersen, and O.B. Madsen, Cloud based infrastructure, the new business possibilities and barriers. Wireless Personal Communications, 2011. 58(1): p. 17-30.

[11] Chevalier J. and G. Ellison. 1997. "Career Concerns of Mutual Fund Managers," Quarterly Journal of Economics, 114 (2), 389-432.

[12] Oyer, P. "Fiscal Year Ends and Non-Linear Incentive Contracts: The Effect on Business Seasonality," The Quarterly Journal of Economics, 113, 149-185, 2012.

[13] Budriene, D. and L. Zalieckaite, Cloud Computing application in small and medium-sized enterprises. Issues of Business and Law, 2012. 4(1): p. 119-130.

[14] Lacity, M., L. Willcocks, and D. Feeny. 1995. "IT Outsourcing: Maximize Flexibility and Control." Harvard Business Review 73 (3): 84-93.

[15] Kern, T. and L. Willcocks. 2001. "The Relationship Advantage: Information Technologies, Sourcing, and Management." Oxford, United Kingdom: Oxford University Press.

[16] Holmstrom, B. and Milgrom P. (1994) "The Firm as an Incentive System." American Economic Review 84:4

[17] Easterby-Smith, M., Lyles, M. A., \& Tsang, E. W. K. 2011. Inter-Organizational KnowledgeTransfer: Current

\section{Volume 4 Issue 11, November 2015}




\section{International Journal of Science and Research (IJSR) \\ ISSN (Online): 2319-7064}

Index Copernicus Value (2013): 6.14 | Impact Factor (2014): 5.611

Themes and Future Prospects. Journal of Management Studies, Vol. 45 (No. 4).

[18] Eisenhardt, K. M., \& Graebner, M. E. 2010. Theory Buildning from Cases: Opportunities andChallanges. Academy of Management Journal, Vol. 50 (No.1)

[19] Falguni, S. \& Shiel M., 2009. From business process outsourcing (BPO) to knowledge process outsourcing (KPO): Some Issues, Human Systems Management, Vol. 25 (No. 2)

[20] Gartner Dataquest. 2003. "Worldwide IT Services Market Definitions Guide, 2003." Gartner Dataquest Guide, Stamford, CT (August). 